\title{
Iron deposits in the chronically inflamed central nervous system and contributes to neurodegeneration
}

\author{
Hjalte Holm Andersen • Kasper Bendix Johnsen • \\ Torben Moos
}

Received: 8 August 2013 / Revised: 8 October 2013 / Accepted: 28 October 2013 / Published online: 12 November 2013

(C) The Author(s) 2013. This article is published with open access at Springerlink.com

\begin{abstract}
Neurodegenerative disorders are characterized by the presence of inflammation in areas with neuronal cell death and a regional increase in iron that exceeds what occurs during normal aging. The inflammatory process accompanying the neuronal degeneration involves glial cells of the central nervous system (CNS) and monocytes of the circulation that migrate into the CNS while transforming into phagocytic macrophages. This review outlines the possible mechanisms responsible for deposition of iron in neurodegenerative disorders with a main emphasis on how iron-containing monocytes may migrate into the CNS, transform into macrophages, and die out subsequently to their phagocytosis of damaged and dying neuronal cells. The dying macrophages may in turn release their iron, which enters the pool of labile iron to catalytically promote formation of free-radical-mediated stress and oxidative damage to adjacent cells, including neurons. Healthy neurons may also chronically acquire iron from the extracellular space as another principle mechanism for oxidative stress-mediated damage. Pharmacological handling of monocyte migration into the CNS combined with chelators that neutralize the effects of extracellular iron occurring due to the release from dying macrophages as well as intraneuronal chelation may denote good possibilities for reducing the deleterious consequences of iron deposition in the CNS.
\end{abstract}

H. H. Andersen and K. B. Johnsen contributed equally to this work.

H. H. Andersen · K. B. Johnsen · T. Moos ( $\triangle)$

Laboratory for Neurobiology, Biomedicine Group, Department of Health Science and Technology, Aalborg University, Fr. Bajers Vej 3B, 1.216, 9220 Aalborg East, Denmark

e-mail: tmoos@hst.aau.dk
Keywords Blood-brain barrier - Cell death · Iron accumulation $\cdot$ Macrophage $\cdot$ Neurodegeneration $\cdot$ Nitric oxide $\cdot$ Phagocytosis
Abbreviations
CNS Central nervous system
DMT1 Divalent metal transporter 1
IL Interleukin
PKAN Pantothenate kinase-associated neurodegeneration
NADPH Nicotinamide adenine dinucleotide phosphate
NO Nitric oxide
RNS Reactive nitrogen species
ROS Reactive oxygen species
TNF- $\alpha$ Tumor necrosis factor $\alpha$
6-OHDA 6-hydroxydopamine

\section{Introduction}

Neurodegenerative disorders are accompanied by inflammation and iron deposition

The most prevalent neurodegenerative disorders of the central nervous system (CNS) are characterized by their chronic affection of specific neuronal nuclei or regions, which leads to various clinical phenotypes (Table 1). Collectively, the loss of neurons in neurodegenerative disorders leads to a gradual loss of functional capacity with largely irreversible symptoms. The time course from the initiation of neuronal cell death to the appearance of clinical symptoms varies but generally decades span until a sufficient amount of neurons are affected, which opens therapeutic possibilities, the focus being to halt further neuronal loss [1]. 
Table 1 Neurodegenerative disorders with inflammation and accumulation of iron- and ferritin-containing macrophages

\begin{tabular}{|c|c|c|c|}
\hline Disorder & $\begin{array}{l}\text { Pathological features associated with neuronal } \\
\text { degeneration }\end{array}$ & $\begin{array}{l}\text { Affected CNS region accompanied by iron } \\
\text { accumulation }\end{array}$ & References \\
\hline Alzheimer's disease & $\begin{array}{l}\text { Intracellular deposition of neurofibrillary } \\
\text { tangles containing hyperphosphorylated } \\
\text { tau-protein and extracellular deposition of } \\
\text { amyloid }\end{array}$ & Cerebral cortex, hippocampus & {$[138-143]$} \\
\hline Parkinson's disease & $\begin{array}{l}\text { Aggregate-like structures formed by alpha- } \\
\text { synuclein in affected dopaminergic neurons } \\
\text { leading to formation of solid inclusion bod- } \\
\text { ies known as Levy Bodies }\end{array}$ & Substantia nigra, striatum & {$[61,144-152]$} \\
\hline Huntington's disease & $\begin{array}{l}\text { Mutation in the gene encoding the huntingtin } \\
\text { protein leading to accumulation of aggre- } \\
\text { gates containing fragments of huntingtin in } \\
\text { spiny neurons }\end{array}$ & Striatum & {$[125,153-155]$} \\
\hline Amyotrophic lateral sclerosis & $\begin{array}{l}\text { Affection of motor neurons caused by compro- } \\
\text { mised production of superoxide dismutase }\end{array}$ & Cerebral cortex, spinal cord & {$[156-160]$} \\
\hline Wilson's disease & $\begin{array}{l}\text { Mutation in the gene encoding a copper-trans- } \\
\text { porting protein ATP7B }\end{array}$ & Striatum & {$[161-165]$} \\
\hline PKAN & $\begin{array}{l}\text { Autosomal recessive disease involving mul- } \\
\text { tiple genes characterized by excessive iron } \\
\text { accumulation in the CNS }\end{array}$ & Striatum & {$[166-170]$} \\
\hline
\end{tabular}

$C N S$ central nervous system, $P K A N$ pantothenate kinase-associated neurodegeneration

Neurodegenerative disorders are also adjoined by various degrees of aseptic inflammation and iron accumulation [2-5]. Inflammatory cells are often present in the vicinity of the affected neurons with varying appearance ranging from robust in Alzheimer's disease to somewhat slighter in Parkinson's disease and amyotrophic lateral sclerosis (ALS). The inflammatory process accompanying the degenerating involves glial cells of the CNS, mainly astrocytes and microglia, and monocytes of the circulation that migrate into the CNS to transform into phagocytic macrophages [6-11]. The presence of phagocytic monocytes migrating into the CNS together with local recruitment of activated microglia denotes a prominent apparatus for killing and phagocytosis of damaged and dying neurons [12].

Characteristically, all disorders mentioned in Table 1 also lead to iron accumulation in the areas affected by neurodegeneration; a feature different from that of the aging CNS, which also increasingly accumulates iron but without adjoining inflammation [13-17]. Iron-containing inflammatory cells, including microglia and macrophages, are consistently present in inflamed brain tissue, suggesting the latter as sources for both iron donation and contribution to production of reactive oxygen species (ROS) via release of free radicals as part of their respiratory burst activity [18, 19] (Fig. 1).

\section{Outline}

The changes in the concentration of transient metals like iron, copper, and zinc with increasing age are general phenomena with the increase in iron being the most notable $[3,15]$. The sources explaining the additional increase in iron in neurodegeneration are reasonably mainly external. Migration of inflammatory cells from the periphery thus may pave the way for the iron accumulation known to take place in the degenerating CNS, as monocytes that transform into tissue macrophages while migrating passed the blood-brain barrier into the CNS contain a high concentration of labile iron and the iron-storing protein ferritin capable of binding approximately 4,500 atoms of iron to each ferritin molecule $[18,20]$. We hypothesize that macrophages, which participate in the phagocytosis of damaged and dying cells, are likely to die out themselves, leading to the release of their iron content inside the CNS. The iron could transform from the repository of ferric iron present inside ferritin to the more available but also labile ferrous iron that might contribute to production of ROS.

Apart from the interests in the contribution of iron for ROS production, little activity has been devoted to the mechanisms underlying the causes of deposition of iron in CNS areas affected with neurodegeneration. The main topic of this review is therefore to cover the significance of the iron carried into the CNS by circulatory monocytes during the process of inflammation, its contribution to neurodegeneration, which clearly occurs in mechanisms different from the handling of the increasing levels of iron in the CNS during normal aging and the therapeutic potential of preventing migration of iron-containing phagocytic macrophages into the CNS. 


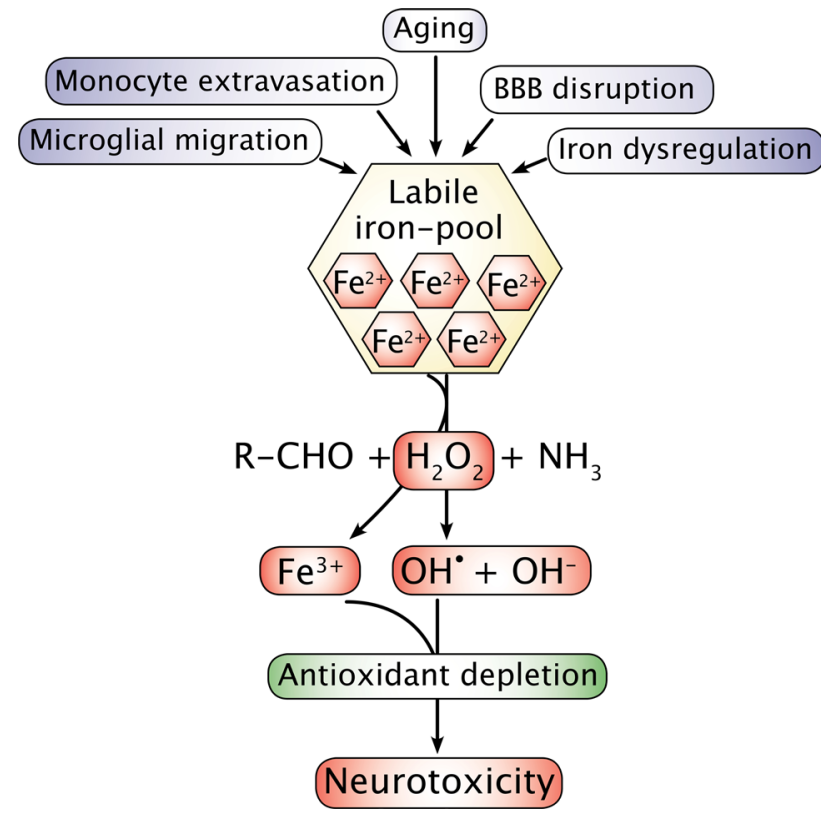

Fig. 1 Overview of major events that lead to iron accumulation in the central nervous system. Dysregulation of cellular iron homeostasis is likely to happen if ferritin expression is hampered leading to a failure in the binding of residual iron. Iron may also pathologically accumulate inside cells due to inhibition of ferroportin mediated by hepcidin (see also text and Fig. 5). Iron accumulating in cells is likely to play a significant role for initiating neurodegeneration via promoting free radical formation by Fenton chemistry. Ferrous iron $\left(\mathrm{Fe}^{2+}\right)$ of the labile iron pool gets catalyzed to ferric iron $\left(\mathrm{Fe}^{3+}\right)$ in a chemical reaction mediated by hydrogen peroxide $\left(\mathrm{H}_{2} \mathrm{O}_{2}\right)$ formed as a byproduct of oxidative metabolism, which leads to formation of hydroxide radical $\left(\mathrm{OH}^{*}\right)$. Depletion in antioxidants inside the cell may fail to scavenge hydroxide radicals and propagate neurotoxicity. $B B B$ blood-brain barrier

\section{Ferritin concomitantly increases in the normal aging brain to scavenge excess iron}

Throughout life, the CNS continuously takes up iron from the circulation by means of receptor-mediated endocytosis of iron-transferrin by brain capillary endothelial cells denoting the blood-brain barrier [21]. The CNS does not excrete iron to the same extent, explaining why the CNS's turnover of iron is extremely low [16, 22]. Reflecting the increasing iron concentration of the aging CNS, iron distributes to all cell types but its detection is hampered by that only iron on its oxidated ferric form can be detectable using histological approaches. Neuronal iron almost exclusively appears in neurons on its ferrous form [23] and does not appear in neurons as ferric iron until aging [23-25]. The cells of the normal aging CNS generally seem capable of handling the increasing iron as they readily respond by increasing their content of ferritin [26]. At the cellular level, the main feature of the aging CNS is that oligodendrocytes substantially increase their ferritin protein expression, which is a dramatic change that represents a raise from virtually no expression during development through an intermediate in the normal adult CNS [27]. Neurons of many brain regions also increase their iron and ferritin content with increasing age, but in a much more heterogeneous pattern than seen in oligodendrocytes, suggesting that the handling of iron by neurons differs among various regions of the CNS. Microglia also increasingly expresses ferritin with aging, whereas astrocytes paradoxically maintain a virtual complete lack of ferritin protein in the development CNS and throughout adulthood and aging despite the fact that they have the capacity to take up iron [28].

Mechanistically, being part of the Fenton and HaberWeiss reactions iron can contribute to neuronal oxidative stress and damage by participating as ferrous iron, i.e., on its reduced form) (Fig. 1). However, as the increasing concentration of iron is reflected by a parallel increase in ferritin in the aged CNS, iron is likely to occur on its oxidized ferric form due to the ferroxidase activity denoted by ferritin [29]. Hence, the ready translation of ferritin mRNA in response to increasing iron levels as well as the enormous capability to bind iron makes it likely that sufficient ferritin expression is proper relative to the cellular level of iron during aging, which thus prevents ferrous iron from participating in unwanted ROS formation [26, 29].

Concomitant to the increasing content of iron of the aging CNS, ROS formation also increases, which is attributed to a lower functioning of the enzymes of the mitochondrial respiratory chain in addition to a weakened antioxidative defense from molecules such as glutathione $[30,31]$. Hence, while important to scavenge the risks of the increasing iron for catalyzing free radicals, ferritin is simultaneously at risk of being damaged by ROS itself, which could release iron from ferritin and subsequently allow unbound iron to enter the pool of labile iron known to be chemically much more reactive than ferritin-bound iron [29, 32]. The increasing ROS formation could also hamper the functioning of iron-responsive proteins or their transcription, which may further impede the regulation of ferritin mRNA translation [33]. The risk is therefore that the increased ROS formation in the aging CNS, incompletely compensated by an antioxidant response, damages ferritin with a resulting release of iron and leading to a further increase in ROS production, hence creating a vicious cycle [29, 34]. Human cases and animal models mutated in ferritin achieve a neurodegenerative state supporting that mismatch in the capability to increase the expression of ferritin in response to increasing iron leads to neuropathology $[34,35]$. 


\section{Oxidative stress formation in the inflamed CNS receives a significant contribution from iron-containing macrophages}

During the processes of oxygen metabolism and ATP formation, mitochondria form ROS and reactive nitrogen species (RNS) as by-products [30, 36, 37], and oxidative stress occurs when the formation of ROS and RNS exceeds the elimination capacity of antioxidative defense system [38, 39]. The CNS receives approximately $20 \%$ of the blood supply of the entire body, and the extraction of oxygen from the blood by the CNS is concomitantly high, making the microenvironment of the CNS rich in oxygen radicals [40]. The tissue of the CNS is rich in peroxidized fatty acids, and even though the cells of the CNS also harbor an antioxidant defense system, the CNS is highly prone for impact by ROS and RNS [41]. Oxidative stress generally plays a role in disease pathogenesis in consequence of distressed metabolism in the CNS because of the toxicity of ROS produced in neurons and inflammatory cells. Many cellular biochemical reactions are responsible for the production of ROS and also RNS in the presence of nitric oxide (NO). The ROS are free radicals of great physiological importance for cells of the innate immune system like monocytes and macrophages functioning to eliminate invading pathogens and dying cells following phagocytosis, while migrating into the CNS in various disease conditions $[2,4-8]$. However, the ROS released from monocytes and macrophages are also potentially harmful to tissues of the CNS, because of their ability to react with almost any cellular component including DNA, lipids, and proteins [42].

The ROS-producing macrophages entering the brain can be functionally sub-categorized into two distinct groups; the pro-inflammatory M1 phenotype and the anti-inflammatory M2 phenotype [43, 44]. Different iron handling between these subgroups of macrophages can be observed in various conditions with chronic inflammation outside the CNS. While activated M1 macrophages readily increase their iron-content, e.g., via DMT1, M2 macrophages are characterized by a much lower iron content due to continuous release of iron through the iron-exporter ferroportin $[44,45]$. Being resident macrophages, microglia can also be subdivided into M1 and M2, both of which have been described in areas of neurodegeneration [8]. The participation from each of these subtypes in chronic neurodegenerative disorders are generally less accounted for compared to the macrophages of peripheral tissues, and therefore cannot be taken into consideration on the distribution and functionality of macrophages entering the brain [8]. However, evidence from transgenic Alzheimer's disease mice suggests that a phenotypic shift from M2 to M1 microglia occurs in models of prolonged neuroinflammation potentially aggravating neuronal degeneration with increasing age [46].
Furthermore, inflammatory stimulation of microglia leads to expression of DMT1 (normally undetectable in resting microglia), which possibly accounts for the increased iron content of activated microglia in regions affected by neurodegeneration [47].

ROS are not only produced by mitochondria but also by nicotinamide adenine dinucleotide phosphate (NADPH) oxidase, an enzyme found in the plasma membrane of all cell types of the CNS, which forms superoxide when metabolizing molecular oxygen [48]. There is strong evidence that NADPH oxidase is upregulated in affected regions during neurodegeneration, e.g., in an experimental model of Parkinson's disease, activation of macrophages and microglia induced by NADPH oxidase triggered a subsequent production of ROS, thus damaging adjacent neurons, suggesting that the inflammatory process affecting a single region may spread to adjacent regions and hamper otherwise unaffected/healthy neurons [49-51]. Furthermore, depletion of the peripheral functioning monocytes may lead to improved neural outcome, indicating that migration of monocytes into the CNS is of significance [52, 53].

Another possible contributor to the oxidative environment in neurodegenerative disorders is NO released from CNS macrophages. The NO can diffuse into neurons from the vicinity of the macrophages and catalyze the formation of the damaging pro-oxidant peroxynitrite via chemical reaction with neuronal superoxide (Fig. 2) [54-59]. NO is also known to interact directly on the binding of iron to ferritin, as NO can release iron from ferritin, causing iron to appear on reactive loosely bound forms [60].

The migration of monocytes into the CNS is dramatically increased in virtually any condition with pathology inside the CNS (Fig. 3) [6-11]. Concomitantly to the increase in this migration, the concentration of iron increases in affected CNS regions, e.g., the concentration of iron increases in the substantia nigra and striatum in Parkinson's disease, in hippocampal and many forebrain regions in Alzheimer's disease, and in the striatum in Huntington's disease [61-63], which makes it obvious to suggest that the migration of iron-containing monocytes into the diseased CNS explains the increasing concentration of iron, which will be dealt with in the following section.

\section{Iron-mediated pathology in neurodegeneration as interplay between increased deposition, oxidative stress formation, and impaired iron efflux}

In accordance with our hypothesis, accumulation of iron in the CNS during neurodegenerative diseases could be attributable to inflammatory cells migrating into the affected areas and deposit iron [5]. Other possible sources 
Fig. 2 Macrophages migrating into the brain release nitric oxide radicals $\left(\mathrm{NO}^{\circ}\right)$, a process that involves the catalytic oxidation of ferrous iron. $\mathrm{NO}^{\circ}$ is capable of diffusing pass the cellular membranes and into neurons where it can react with superoxide $\left(\mathrm{O}^{\circ-}\right)$ and promote formation of the highly reactive and toxic peroxynitrite $\left(\mathrm{ONOO}^{-}\right)$

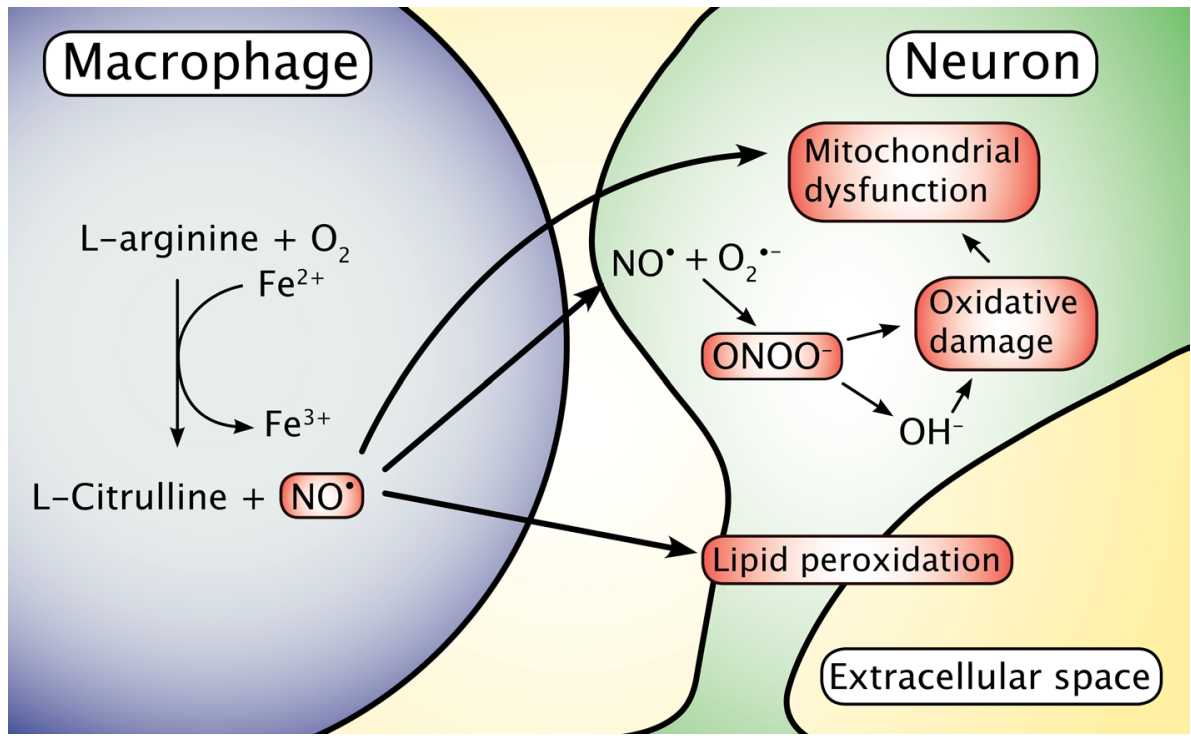

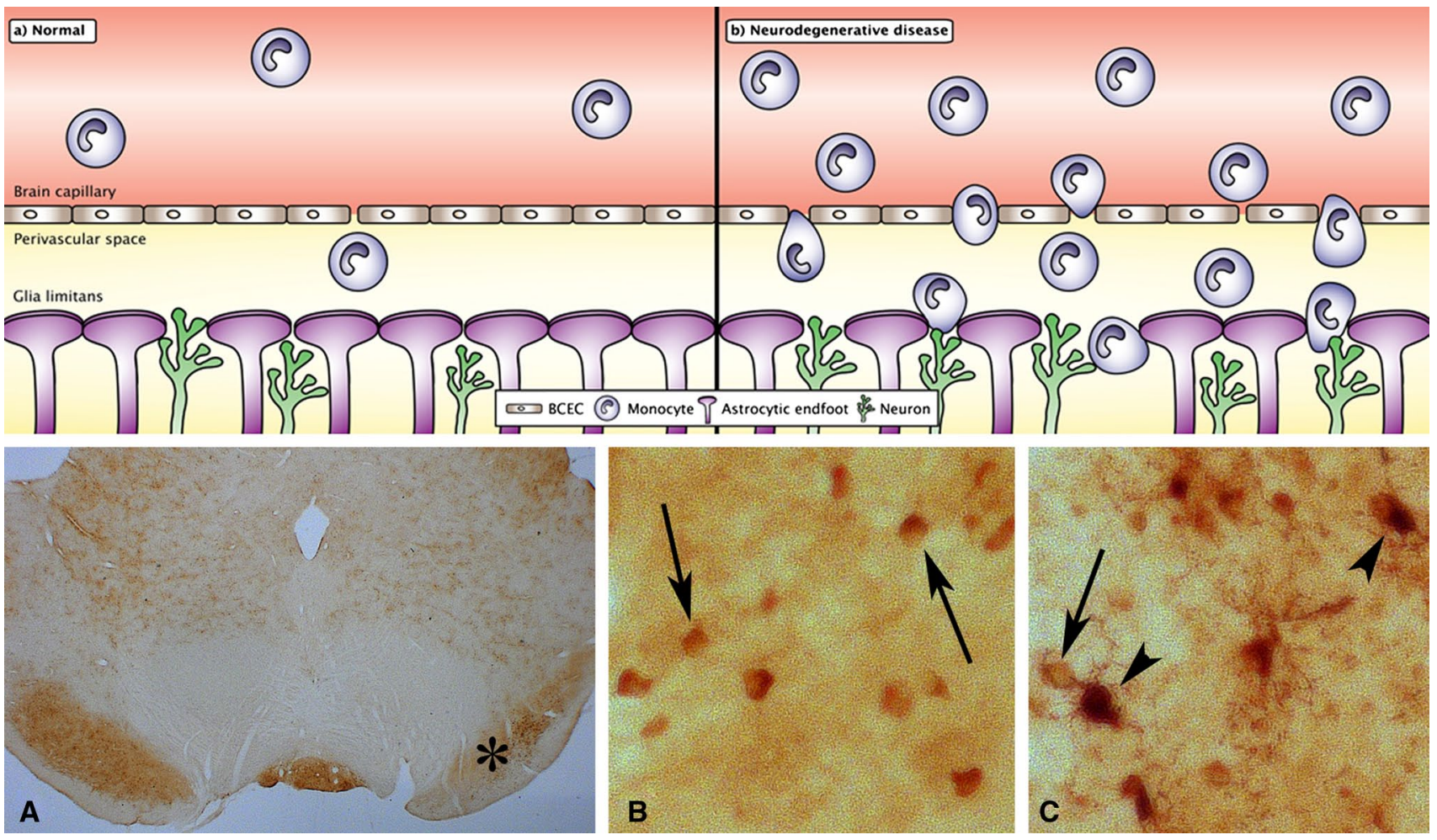

Fig. 3 Migration of monocyte into the normal (a) and neurodegenerating (b) brain. The monocytes migrate through the brain capillaries that form the blood-brain barrier even in normal conditions. In conditions with pathology, the migration of monocytes into the brain through the blood-brain barrier is much more pronounced. In consequence of this migratory process, the monocytes transform into macrophages with immediate access to neuronal projections and astrocytic end-feet forming the so-called glia limitans, demarcating the brain perivascular space. $B C E C$ brain capillary endothelial cells. Bottom Inflammatory cells in the substantia nigra reticulata identified by ferritin labeling. Rats were injected unilaterally into the striatum with a glutamate agonist to induce degeneration in the striatal nigral pathway. The loss of striatal innervation of the substantia nigra reticulata leads to a gradual degeneration that is followed by chronic inflammation and iron accumulation (Sastry and Arendash, 1995). A The mesencephalon with the affected substantia nigra reticulata indicated (asterisk). B In the substantia nigra reticulata of the unaffected side, the ferritin-containing cells are virtually only seen in oligodendrocytes (arrows), whereas in the affected substantia nigra reticulate $(\mathbf{C})$, ferritin-containing cells are identified as monocytes and macrophages (arrowheads) and oligodendrocytes (arrow) (Thomsen and Moos, in preparation). Magnification: A $\times 5$. B-C $\times 200$ 
for chronic iron deposition are due to changes in the physiological transport of iron across the blood-brain barrier and an impaired cellular capability to export iron. The following paragraphs are devoted to these issues via a sequential coverage of: (i) The blood-brain barrier in inflammatory conditions; (ii) accumulation of inflammatory cells and iron deposition in both non-neuronal and neuronal tissues; (iii) transport of non-cellular iron across the blood-brain barrier in chronic CNS inflammation, and (iv) compromise in the capability to export iron from the CNS.

The blood-brain barrier in inflammatory conditions

The blood-brain barrier, consisting of non-fenestrated capillary endothelial cells with their intermingling tight junctions, denotes a morphological interface situated between the circulation and the CNS parenchyma [64, 65]. These endothelial cells prevent large, especially lipid insoluble, molecules from entering the CNS and also closely regulates the level of nutrients, vitamins, and minerals that enters the CNS. An extended interface between the blood and the CNS is formed by the brain capillary endothelial cells, their basement membrane, and glial cells such as astrocytes and pericytes, which together form the so-called neurovascular unit [64]. While not directly involved in regulating barrier permeability, these glial cell types are important for the induction and maintenance of the barrier characteristics of the brain capillary endothelial cells [66].

The integrity of the blood-brain barrier is reportedly compromised and thought to play a significant role in many different neurological disorders, including epilepsy, migraine, stroke, and various neurodegenerative disorders [67-70]. Among the latter, disruption of the blood-brain barrier was described in Alzheimer's disease, Parkinson's disease, and amyotrophic lateral sclerosis [71-74]. In Alzheimer's disease, inflammation of the cerebral vasculature seems to be an early event in the progression of neuroinflammation and $A \beta$ deposition [75, 76]. Early inflammation of the blood-brain barrier was recently observed together with changes in permeability and upregulation of MECA-32 and selectin expression in experimental models of neurodegeneration $[67,68,70]$. Hence, activation of the endothelium coincides with early leakage of the bloodbrain barrier, which may allow for inflammatory cells like monocytes and macrophage to enter the CNS locally early in disease to initiate deposition of iron. Inflammation of the periphery may also lead to opening of the blood-brain barrier, increased migration of monocytes into the CNS, microglial activation, damage to dopaminergic neurons, and exaggerated deposition of iron inside the CNS [47, 52, 53].
Deposition of iron in non-neurological disorders is associated with ROS formation and chronic inflammatory pathology

Migration of monocytes through an endothelial barrier is characteristic for several chronic inflammatory conditions in non-neuronal tissues. The monocytes harbor the largest pool of labile iron among the hematopoietic cells [18]. This labile iron pool is important for the adhesion of the monocytes to endothelial cells, and subsequently their migration through endothelium in non-neuronal tissues and their transformation into macrophages [77, 78]. This labile iron pool is, however, loosely bound to proteins and prone to participate in cellular destructive reactions when monocytes are attracted to regions of tissue inflammation [18]. Inflammation and essential metals are highly entwined with respect to diverse peripheral chronic inflammatory disorders. The role of iron as a potential catalyst of inflammation and degeneration in non-neuronal tissues has been investigated intensely with regards to the chronic inflammation that occurs in various conditions such as joint diseases, atherosclerosis, and inflammatory bowel disorders. The literature discloses evidence that iron deposits in synovial fluid in numerous inflammatory and degenerative joint disorders, e.g. rheumatoid arthritis, osteoarthritis, hemophilic synovitis, and seronegative arthritis [79-86]. In these joint diseases, just as in inflammatory disorders of the bowel, accumulating iron seemingly takes on a part as a villain to maintain and exacerbate chronic inflammation.

Perhaps the most obvious example of how monocytes and macrophages may deposit iron and exacerbate pathology is seen in atherosclerosis, which shares similarities with the inflammation of the CNS with respect to the presence of endothelial abnormalities, transmigration of monocytes through activated endothelial cells, local recruitment of macrophages to the sites of inflammation, and accumulation of iron [87]. In atherosclerosis, the process of chronic vascular inflammation gets significant contribution from circulating iron-containing monocytes that migrate into the sub-endothelial compartment attracted primarily by the endothelial expression of adhesion molecules like vascular cell adhesion molecule-1 (VCAM-1), intercellular adhesion molecule-1 (ICAM-1), and chemo-attractant chemokine ( $\mathrm{C}-\mathrm{C}$ motif) ligand 2 (CCL2), molecules also being expressed by the activated brain endothelium in inflammatory conditions in the CNS [88-90]. In the inflamed subintimal zone of the arteries, the labile iron present in macrophages is likely to play a detrimental role as it prompts formation of ROS and free radicals through the Fenton and Haber-Weiss reactions [91, 92]. Accumulation of iron in non-neurological diseases, particularly atherosclerosis, thus supports the notion that inflammatory cells 
migrate into inflamed tissues where they deposit iron and thereby contribute to ongoing inflammation.

The accumulation of inflammatory cells and iron deposition in neuronal tissue

Monocytes migrate through the blood-brain barrier in brain ischemia, transform into tissue macrophages, and carry iron into the brain where it exerts deleterious effects [93, 94]. The migrating monocytes therefore denote a plausible source of iron for the affected areas in neurodegenerative disorders (Fig. 3). Similar to the events taking place during inflammation in non-neuronal tissues, in inflammatory conditions of the CNS, the expression of selectins by brain capillary endothelial cells leads to attachment of monocytes that "roll" in the direction of the circulation towards the endothelial surface. After adhesion to immobilized chemokines, the integrins of the migrating monocytes bind to ligands, e.g., ICAM-1, which in turn leads to a tighter adhesion of the monocytes to the surface of brain capillary endothelial cells. Subsequently, protruding processes of the monocytes are likely to facilitate the search for chemokines expressed on the abluminal surface of the brain capillary endothelial cells, which enable their further entry into the perivascular space when passing though the brain endothelium. Here, the monocytes may additionally secrete matrix metalloproteinases to degrade the extracellular matrix of the basement membrane or bind to the extracellular matrix through $\beta 1$-integrin, thereby facilitating the final migration into the brain parenchyma [95]. The presence of $A \beta$, either on its soluble form near the luminal side of brain capillary endothelial cells or on its aggregated form on their abluminal side, significantly potentiates the transmigration of monocytes in an in vitro model of the blood-brain barrier
[96] and clearly suggests that monocytes of the periphery enter the CNS in pathological conditions.

There is strong evidence from experimental studies supporting that pathological conditions of the CNS leads to iron accumulation in affected brain regions, e.g., chemical lesion of the striatum leads to degeneration accompanied by manifest inflammation and iron deposition not only in the striatum but also significantly in the substantia nigra that communicate bilaterally with the striatum [5]. Hence, in good agreement with our hypothesis, macrophages migrating into the substantia nigra may phagocytose damaged neurons and subsequently deposit iron. Therefore, the chronic migration of monocytes could also play an important role in the progression of neurodegenerative disorders (Fig. 4) [60]. While acting as activated phagocytic cells, the macrophages release NO that can directly promote iron release from ferritin [59]. Moreover, the macrophages will eventually die out by apoptosis to terminate the inflammatory process unless chronic stimuli precedes [59, 97, 98]. This will lead to release of the labile iron present inside the macrophages, which subsequently becomes accessible for both already damaged and otherwise healthy neurons (Fig. 4). The iron released from dying macrophages can play a significant role not only for direct neuronal damage and resulting cell death but also by means of ROS-mediated post-translational affection of proteins to gradually perturb their function, e.g., by promoting neuronal fibril and aggregate formation as seen in Parkinson's disease that eventually could also lead to neuronal cell death, but in a much more long-lasting scenery $[99,100]$.

In the resting brain, entering macrophages can differentiate into microglia $[6,11,101]$. Activation of microglia is a well-described phenomenon occurring in a number of neurodegenerative disorders due to molecular release

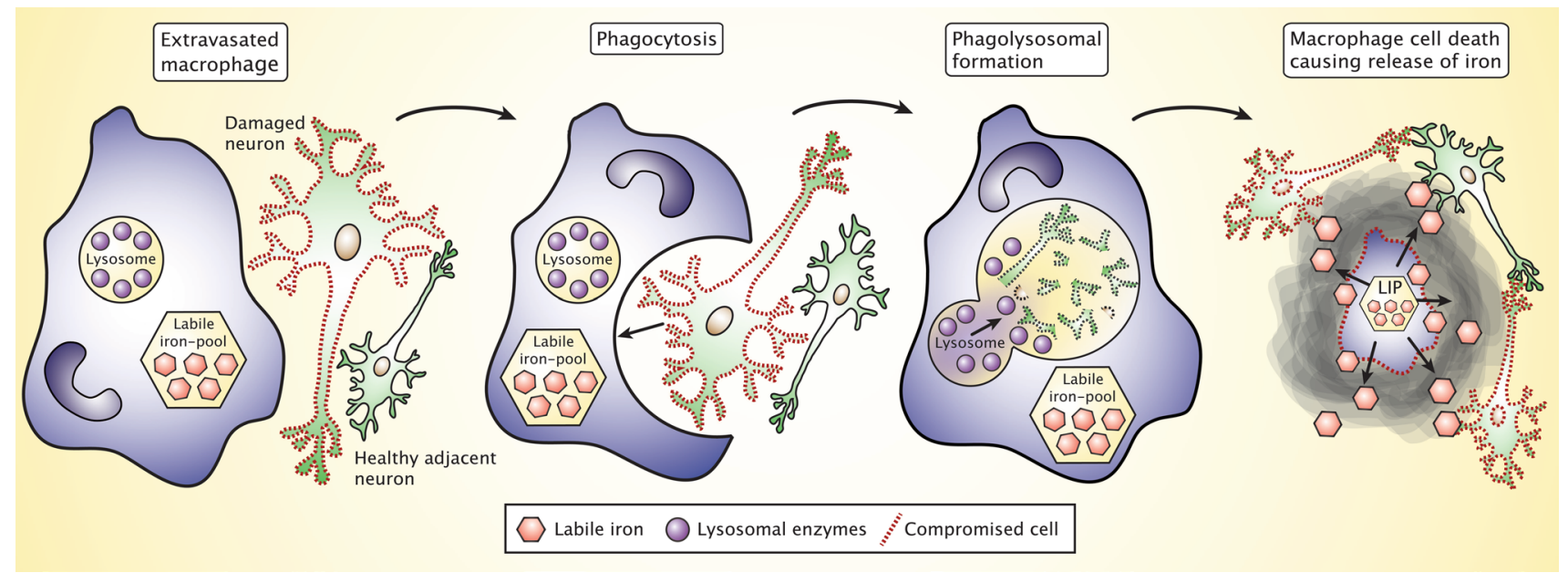

Fig. 4 Extravasated macrophages phagocytose and degrade damaged neurons and subsequently die to terminate their function, which leads to the release of iron into the extracellular space of the CNS on a low molecular weight form 
from dying neurons of ROS, chemokines, interleukins, and tumor necrosis factor $\alpha(\mathrm{TNF}-\alpha)[8,102]$ that leads to the migration of the microglia towards the regions affected of neurodegeneration, where they participate in the phagocytosis and destruction of dying neurons until they die out themselves by apoptosis [12, 97, 103-105]. Microglia contain relatively high amounts of iron bound to ferritin and the migration of microglia to the degenerating regions therefore make a significant contribution to the local increase in iron by a mechanism similar to the mechanism proposed to occur in macrophages [106]. Moreover, the activation of microglia is known to facilitate the release of labile iron from the ferritin complex, hereby introducing free iron to neurons in the areas of disease [107].

The transport of non-cellular iron across the blood-brain barrier in chronic inflammation of the CNS

The regulation of iron uptake in the brain is a tightly controlled process involving binding of transferrin to the brain capillary endothelial cells followed by endosomal uptake of holo-transferrin [108]. On the abluminal surface of the brain capillary endothelial cells, the microenvironment of the CNS could drive the release of iron, which would subsequently be bound to parenchymal transferrin, citrate or ATP, and passes into the brain interstitium for uptake by neuronal and glial uptake. Inflammatory activity within affected regions of the CNS could lead to iron being released from macrophages that could bind to transferrin in the extracellular space and enter neurons by means of receptor-mediated uptake of iron transferrin or by nontransferrin bound iron uptake, which would also apply to glial cells [109].

The fact that increasing the concentration of iron in plasma still fails to improve the entry of iron into the CNS both experimentally or in human conditions with hemochromatosis indicates that the brain capillary endothelial cells with intact blood-brain barrier properties are able to down-regulate their expression of transferrin receptors in response to the increasing availability [108]. By contrast, in conditions with neurodegeneration and inflammation of the CNS, there is evidence for an increased opening of the blood-brain barrier leading to paravascular passage of macromolecules locally in regions with affected neurons $[68,110]$.

The activation of the endothelium in Alzheimer's disease with down-regulation of tight junction expression precedes the deposition of $\mathrm{A} \beta$ but coincides with early blood-brain barrier leakage, which could represent the earliest stages of disease $[75,76]$. This raises the question if paraendothelial transfer of holo-transferrin through these leakages may contribute to the increased deposition of iron in many neurological disorders. An increase in iron entry through a compromised blood-brain barrier with increased paraendothelial transfer was recently reported in an experimental model of transient forebrain ischemia [93, 94], but quantitative evidence that could justify whether iron-transferrin entering the brain due to a compromised blood-brain barrier to yield significances in iron accumulation is still needed.

Compromise in the capability to export iron from the CNS

In addition to its participation in intestinal absorption and circulatory iron homeostasis via expression in duodenal enterocytes, hepatocytes, and macrophages, ferroportin is also expressed in neurons of the CNS with significant regional variations [111-113]. Ferroportin is the only described protein known to mediate cellular efflux of iron [114], which would make a mismatch in the functionality of ferroportin in the CNS a possibility for iron to get trapped inside neurons, leading to their lack of capability to excrete iron. In turn, this incapability to export iron from cells would lead to accumulation of iron inside CNS and pose neurons to an increased risk for ROS-mediated damage.

Ferroportin expression is post-transcriptionally regulated via interaction between iron-regulatory proteins and an iron-responsive element present in the $3^{\prime}$-end of its mRNA, indicating that ample presence of iron leads to stabilization and increased half-life of ferroportin mRNA leading to higher translation [114]. The expression of ferroportin is also post-translationally regulated by the hormone hepcidin, as the binding of hepcidin results in phosphorylation, internalization, and degradation of ferroportin, thus severely altering the ability of the cell to excrete iron [115, 116].

Experimental neurodegeneration has never been correlated directly with changes in neuronal ferroportin expression, but injections of hepcidin into the lateral ventricle of the rat leads to a decrease in neuronal ferroportin, confirming the notion of a degradation of ferroportin in the presence of hepcidin [117]. Hepcidin is secreted from hepatocytes in systemic inflammatory conditions, and provided that pathological activity of the CNS leads to humoral signaling in the circulation, it is predictable that such activity would lead to raise hepcidin in plasma with the likelihood of passing into the brain, provided the integrity of the blood-brain barrier gets compromised. Clearly, a condition with chronic pathology of the CNS leading to migration of iron-containing macrophages and their subsequent demise as discussed in previous paragraphs would make it likely that the neurons could suffer from the accumulation of iron released from dying macrophages combined with the incapability to release iron via ferroportin due to the presence of hepcidin inside the inflamed CNS 
Fig. 5 The macrophages, like monocytes and microglia, are capable of secreting hepcidin into the brain extracellular space. Hepatic hepcidin is synthesized in response to inflammatory signals and secreted into blood plasma from where it can diffuse into the brain in areas with a compromised blood-brain barrier. The hepcidin is capable of binding and inhibiting ferroportin needed for export of iron from neurons, which may result in neuronal iron accumulation and increased the likelihood of neuronal damage via Fenton chemistry

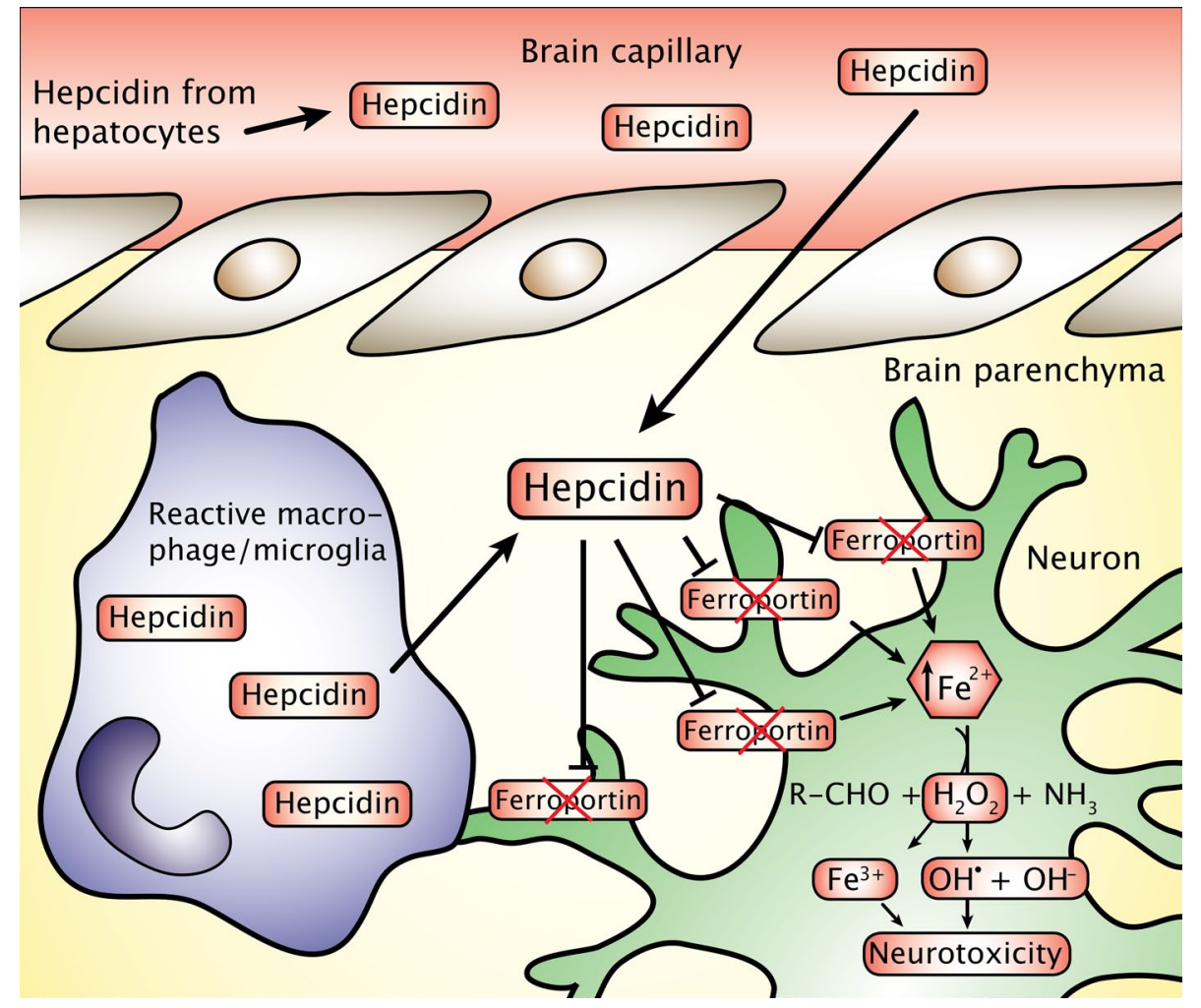

(Fig. 5). This notion gets exaggerated by the fact that the turnover of iron in the CNS is very slow even in the normal brain, which can be attributed to iron being accumulated in cells of the brain rather than being transported out of the brain (cf. [118]).

\section{Pharmacological intervention to limit pathological iron deposition in neurodegenerative disorders}

The chronic setting of iron-containing macrophages migrating into the CNS in affected areas in conditions with neurodegeneration gives rise to deposition of iron that eventual may reach limits that will promote formation of free radicals to an extent uncontrollable by increases in ferritin expression. Therefore, it is reasonable to consider the possibilities of pharmacological intervention to limit the damages of pathological iron deposition. A first strategy will be to directly intervene into the events leading to neuronal degeneration, but the coverage of this option goes beyond this review. Further downstream is the cause of inhibiting migration of monocytes into the brain, followed by antioxidant therapy to neutralize the formation of excess free radicals, and final the possibilities of limiting iron deposition by means of chelator therapy that would serve to reduce iron occurring extracellularly due to degradation of damaged and dying cells including brain macrophages and intracellularly in neurons.
Inhibition of macrophages in neurodegeneration using antioxidant therapy

The local environment in affected areas in neurodegenerative disorders is enriched in oxidants and the load from free radicals is permanently at risk for exaggerating neuronal cell death. The contribution of pro-oxidants can in part be attributed to the action of monocytes migrating through the blood-brain barrier and microglia migrating inside the CNS towards the sites of neurodegeneration. Hence, the inhibition of migration of monocytes into the CNS could be of significance to halt disease progression and contribute to the development of effective therapeutic regimens in conditions with neurodegeneration [119]. The action of migrating macrophages can qualitatively be inhibited by treatment with antioxidants that serve to reduce the load of pro-oxidant molecules, although clinical significance of antioxidant treatment in neurodegenerative diseases is yet to be proven. The impact of corticosteroids and several non-steroid anti-inflammatory drugs on the progression of Alzheimer's disease was tested in a clinical trial, but beneficial effects could not be detected [120, 121]. Among other promising and diverse agents such as co-enzyme Q-10 (mitochondrial enhancer and antioxidant), minocycline (anti-inflammatory agent), and rasagiline (MAO-inhibitor), none has yet made it to the clinic [122]. Minocycline is highly lipophilic and hence readily crosses the blood-brain barrier [123]. This advantage in the pharmacokinetic profile 
would suggest the compound to be preferable for treatment of chronic neurodegenerative disorders, and irrespective of the mechanisms that could be beneficial in the usage of this anti-inflammatory drug, its success in clinical testing will probably depend on the length of the dosage regimen and possibly also that the onset of therapy takes place when the disease is not too progressed. Although pivotal progress has not been made, several compounds affecting oxidant levels were suggested for further exploration for the treatment of Parkinson's disease and research into these compounds and their promising derivatives continues [122, 124]. This also applies to treatment of Huntington's disease, where efforts focus on increasing autophagy and ubiquitination of mutant huntingtin protein $\mathrm{mHtt}$ combined with treatment of antioxidants like co-enzyme Q10 and cysteamine [125, 126].

Iron chelators for neutralizing the effects of iron accumulation in neurodegeneration

Iron chelating agents were examined in various degenerative disorders with iron pathogenically involved, e.g., in Parkinson's disease, coronary heart disease, and general atherosclerosis. Studies in rodents suggest that restriction in iron intake reduces progression in atherosclerotic plaque formation [77, 127, 128], while administration of excess iron on the contrary augments these processes [129]. Furthermore, treatment with the iron chelating agent desferrioxamine has proven successful in reducing iron concentration in atherosclerotic plaques and decreasing atherosclerotic lesion formation in animal models [130, 131]. In neurodegeneration, a principal target for iron chelation is extracellular iron due to degradation of damaged and dying cells including brain macrophages. As stated in the preceding paragraphs, the macrophages entering the CNS are likely to die out by apoptosis when having commenced their function, which will lead to their release of iron into the extracellular space. The iron released in such a condition will likely bind to transferrin or low molecular weight substances like citrate and ATP [118] and be amendable for therapy with extracellularly acting iron chelators, provided these are capable of passing the blood-brain barrier. Conversely, iron accumulating in neurons as part of the general aging and iron taken up in excess from the extracellular space due to the degeneration of other neurons and macrophages will need the action of intracellular iron chelators.

In spite of iron chelators like desferrioxamine and deferiprone having been used beneficially for decades for the treatment of hemochromatosis and iron poisoning, the usage of iron chelators in neurodegenerative disorders has not resulted in pivotal clinical breakthroughs [132]. Desferrioxamine and deferiprone used clinically to treat thalassemia via parenteral injection were shown to successfully reduce striatal DA neuron depletion and behavioral symptoms in the 6-hydroxydopamine (6-OHDA) model of Parkinson's disease after injection into the cerebral ventricles [133, 134]. As desferrioxamine does not penetrate the blood-brain barrier, this drug has obvious limitations for treatment inside the CNS, but it might be valuable for chelation of iron extracellularly in the brain, in particular in pathological conditions with a perturbed blood-brain barrier. This condition does not fully apply to deferiprone that crosses the intact blood-brain barrier to some extent [135]. Interestingly, deferiprone is currently being examined in clinical studies for its capability to reduce disease progression in PKAN [136, 137].

An alternate application of oral iron chelators is to use the oral route, which is particularly relevant for lipophilic drugs. The lipophilic molecule deferasirox was also shown to attenuate the loss of dopaminergic neurons and preserve striatal dopamine in the 6-OHDA model of Parkinson's disease [134]. Deferasirox has been approved by the FDA for therapy in conditions with chronic iron overload. Contrary to the parenteral iron chelators, deferasirox may exert its action inside neurons rather than in the extracellular environment. This indicates that it could be favorable to combine different iron chelators for studies in experimental models with iron accumulation in an attempt to simultaneously chelate iron deposited extracellularly occurring from cellular debris of dying neurons and macrophages and iron accumulating inside neurons due to uptake from the pathologically iron-enriched immediate interstitium. The strategy of combining iron chelators acting on iron present extra- or intracellularly might even benefit from a combination with therapeutics to inhibit migration of iron-containing macrophages into the CNS (Fig. 6).

\section{Conclusions}

For reasons still unknown, the concentration of iron increases in the brain with increasing age. The rise in brain iron content in aging is even higher in neurodegenerative disorders, which is probably a result of the inflammatory process occurring in areas affected by neurodegeneration. The transformation of iron-containing monocytes that migrate across the blood-brain barrier into the CNS while transforming into brain macrophages is in agreement with this notion. As a consequence of the phagocytosis of damaged and dying neurons, the entering macrophages eventually die out, leading to the release of their own content of iron into the brain interstitium from where it will enter the pool of loosely bound iron that catalytically may promote formation of free-radical-mediated stress and oxidative damage to cell membranes in the adjacent environment. Damaged but also healthy neurons may engulf iron of the dying macrophages from extracellular space leading to cellular accumulation with the risk of further promoting 


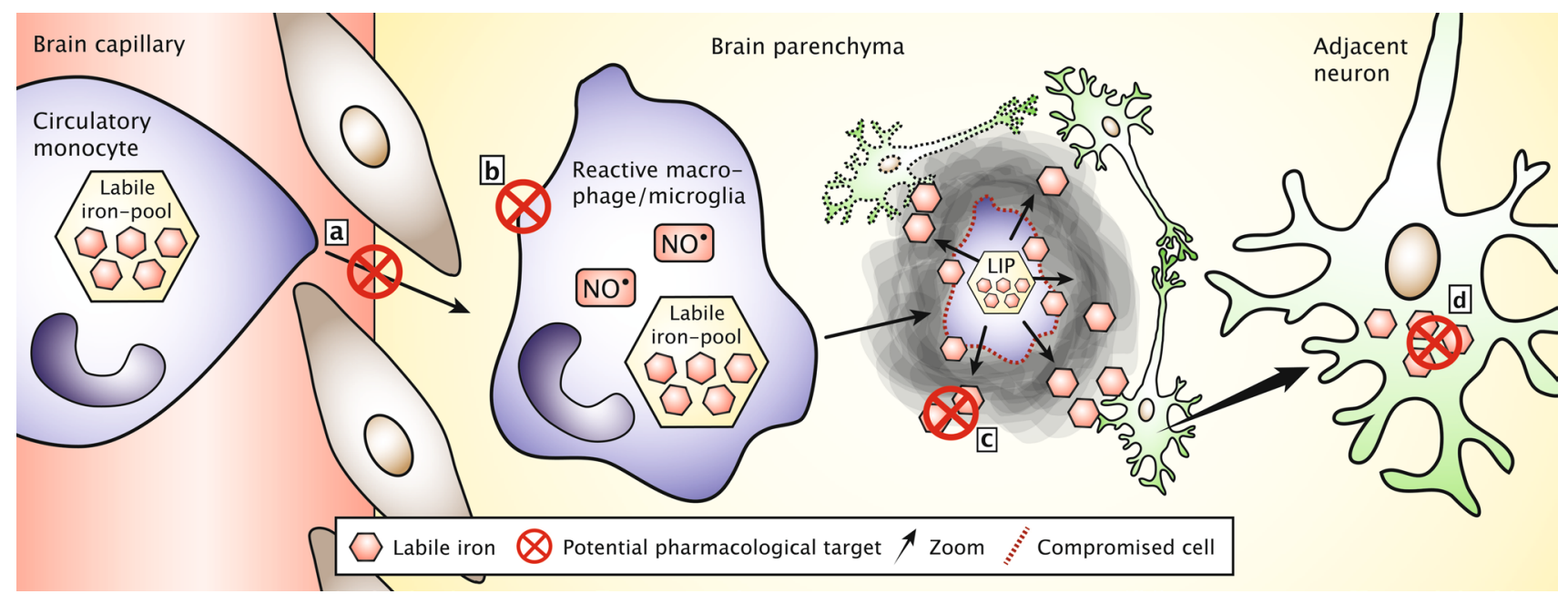

Fig. 6 Potential pharmacological intervention points to inhibit the impact of migrating macrophages on their deposition of iron in the brain. a Inhibition of monocytes migration into the brain via transfer through the brain capillaries. b Inhibition of the functioning of the brain macrophages for phagocytosis and nitric oxide $\left(\mathrm{NO}^{\circ}\right)$ release. c Extracellular chelation of low molecular weight iron released from dying macrophages. $\mathbf{d}$ Intracellular chelation of iron in neurons subsequent to their uptake of low molecular weight iron from the extracellular space neuronal damage. The chronic inflammation and decreased blood-brain barrier integrity accompanying neurodegenerative disorders may be pharmacologically managed via intervention of the monocyte migration into the brain combined with chelator therapeutics that aim to chelate iron released extracellularly due to release from dying macrophages and chelating of iron deposited intracellularly in neurons.

Acknowledgments The most recent results obtained and described by the authors were generated by generous grant support from the Lundbeck Foundation and the Obelske Family Fund.

Open Access This article is distributed under the terms of the Creative Commons Attribution License which permits any use, distribution, and reproduction in any medium, provided the original author(s) and the source are credited.

\section{References}

1. Bredesen DE, Rao RV, Mehlen P (2006) Cell death in the nervous system. Nature 443:796-802. doi:10.1038/nature05293

2. Khandelwal PJ, Herman AM, Moussa CE-H (2011) Inflammation in the early stages of neurodegenerative pathology. J Neuroimmunol 238:1-11. doi:10.1016/j.jneuroim.2011.07.002

3. Kozlowski H, Luczkowski M, Remelli M, Valensin D (2012) Copper, zinc and iron in neurodegenerative diseases (Alzheimer's, Parkinson's and prion diseases). Coord Chem Rev. doi:10.1016/j.ccr.2012.03.013

4. Lassmann H (2011) Mechanisms of neurodegeneration shared between multiple sclerosis and Alzheimer's disease. J Neural Transm 118:747-752. doi:10.1007/s00702-011-0607-8

5. Sastry S, Arendash GW (1995) Time-dependent changes in iron levels and associated neuronal loss within the substantia nigra following lesions within the neostriatum/globus pallidus complex. Neuroscience 67:649-666. doi:10.1016/0306-4522(94)00618-F

6. Milligan CE, Cunningham TJ, Levitt P (1991) Differential immunochemical markers reveal the normal distribution of brain macrophages and microglia in the developing rat brain. $\mathrm{J}$ Comp Neurol 314:125-135. doi:10.1002/cne.903140112

7. Milligan CE, Levitt P, Cunningham TJ (1991) Brain macrophages and microglia respond differently to lesions of the developing and adult visual system. J Comp Neurol 314:136146. doi:10.1002/cne. 903140113

8. Cunningham C (2012) Microglia and neurodegeneration: the role of systemic inflammation. Glia. doi:10.1002/glia.22350

9. Serrano-Pozo A, Mielke ML, Gómez-Isla T et al (2011) Reactive glia not only associates with plaques but also parallels tangles in Alzheimer's disease. Am J Pathol 179:1373-1384. doi:10.1016/j.ajpath.2011.05.047

10. Prinz M, Priller J, Sisodia SS, Ransohoff RM (2011) Heterogeneity of CNS myeloid cells and their roles in neurodegeneration. Nat Neurosci 14:1227-1235. doi:10.1038/nn.2923

11. Bechmann I, Goldmann J, Kovac AD et al (2005) Circulating monocytic cells infiltrate layers of anterograde axonal degeneration where they transform into microglia. FASEB J 19:647649. doi:10.1096/fj.04-2599fje

12. Brown GC, Neher JJ (2010) Inflammatory neurodegeneration and mechanisms of microglial killing of neurons. Mol Neurobiol 41:242-247. doi:10.1007/s12035-010-8105-9

13. Zecca L, Youdim MBH, Riederer P et al (2004) Iron, brain ageing and neurodegenerative disorders. Nat Rev Neurosci 5:863873. doi:10.1038/nrn1537

14. Lee DW, Andersen JK (2010) Iron elevations in the aging Parkinsonian brain: a consequence of impaired iron homeostasis? J Neurochem 112:332-339. doi:10.1111/j.1471-4159.2009. 06470.x

15. Ward RJ, Dexter DT, Crichton RR (2012) Chelating agents for neurodegenerative diseases. Curr Med Chem 19:2760-2772. doi:10.2174/092986712800609689 
16. Dexter DT, Wells FR, Agid F et al (1987) Increased nigral iron content in postmortem parkinsonian brain. Lancet 2:12191220. doi:10.1016/S0140-6736(87)91361-4

17. Sofic E, Riederer P, Heinsen $\mathrm{H}$ et al (1988) Increased iron (III) and total iron content in post mortem substantia nigra of parkinsonian brain. J Neural Transm 74:199-205. doi:10.1007/BF01244786

18. Prus E, Fibach E (2008) Flow cytometry measurement of the labile iron pool in human hematopoietic cells. Cytometry A 73:22-27. doi:10.1002/cyto.a.20491

19. Hayes A, Thaker U, Iwatsubo T et al (2002) Pathological relationships between microglial cell activity and tau and amyloid beta protein in patients with Alzheimer's disease. Neurosci Lett 331:171-174. doi:10.1016/S0304-3940(02)00888-1

20. Theil EC (1987) Ferritin: structure, gene regulation, and cellular function in animals, plants, and microorganisms. Annu Rev Biochem 56:289-315. doi:10.1146/annurev.bi.56.070187.001445

21. Taylor EM, Crowe A, Morgan EH (1991) Transferrin and iron uptake by the brain: effects of altered iron status. J Neurochem 57:1584-1592. doi:10.1111/j.1471-4159.1991.tb06355.x

22. Dallman PR, Spirito RA (1977) Brain iron in the rat: extremely slow turnover in normal rats may explain long-lasting effects of early iron deficiency. J Nutr 107:1075-1081

23. Benkovic SA, Connor JR (1993) Ferritin, transferrin, and iron in selected regions of the adult and aged rat brain. J Comp Neurol 338:97-113. doi:10.1002/cne.903380108

24. Moos T, Trinder D, Morgan EH (2000) Cellular distribution of ferric iron, ferritin, transferrin and divalent metal transporter 1 (DMT1) in substantia nigra and basal ganglia of normal and beta2-microglobulin deficient mouse brain. Cell Mol Biol (Noisy-le-grand) 46:549-561

25. Kaur D, Yantiri F, Rajagopalan S et al (2003) Genetic or pharmacological iron chelation prevents MPTP-induced neurotoxicity in vivo: a novel therapy for Parkinson's disease. Neuron 37:899-909. doi:10.1016/S0896-6273(03)00126-0

26. Focht SJ, Snyder BS, Beard JL et al (1997) Regional distribution of iron, transferrin, ferritin, and oxidatively-modified proteins in young and aged Fischer 344 rat brains. Neuroscience 79:255-261. doi:10.1016/S0306-4522(96)00607-0

27. Cheepsunthorn P, Palmer C, Connor JR (1998) Cellular distribution of ferritin subunits in postnatal rat brain. J Comp Neurol 400:73-86. doi:10.1002/ (SICI)1096-9861(19981012)400:1<73:AID-CNE5>3.0.CO;2-Q

28. Pelizzoni I, Zacchetti D, Campanella A et al (2013) Iron uptake in quiescent and inflammation-activated astrocytes: a potentially neuroprotective control of iron burden. Biochim Biophys Acta 1832:1326-1333. doi:10.1016/j.bbadis.2013.04.007

29. Honarmand Ebrahimi K, Bill E, Hagedoorn P-L, Hagen WR (2012) The catalytic center of ferritin regulates iron storage via $\mathrm{Fe}(\mathrm{II})-\mathrm{Fe}$ (III) displacement. Nat Chem Biol 8:941-948. doi:10. 1038/nchembio.1071

30. Venkateshappa C, Harish G, Mahadevan A et al (2012) Elevated oxidative stress and decreased antioxidant function in the human hippocampus and frontal cortex with increasing age: implications for neurodegeneration in Alzheimer's disease. Neurochem Res 37:1601-1614. doi:10.1007/s11064-012-0755-8

31. de Oliveira DM, Ferreira Lima RM, El-Bachá RS (2012) Brain rust: recent discoveries on the role of oxidative stress in neurodegenerative diseases. Nutr Neurosci 15:94-102. doi:10.1179/1 476830511Y.0000000029

32. Altamura S, Muckenthaler MU (2009) Iron toxicity in diseases of aging: Alzheimer's disease, Parkinson's disease and atherosclerosis. J Alzheimers Dis 16:879-895. doi:10.3233/ JAD-2009-1010

33. Rouault TA (2013) Iron metabolism in the CNS: implications for neurodegenerative diseases. Nat Rev Neurosci. doi: $10.1038 /$ nrn3453
34. Vidal R, Miravalle L, Gao X et al (2008) Expression of a mutant form of the ferritin light chain gene induces neurodegeneration and iron overload in transgenic mice. J Neurosci 28:60-67. doi: 10.1523/JNEUROSCI.3962-07.2008

35. Luscieti S, Santambrogio P, Langlois d'Estaintot B et al (2010) Mutant ferritin L-chains that cause neurodegeneration act in a dominant-negative manner to reduce ferritin iron incorporation. J Biol Chem 285:11948-11957. doi:10.1074/jbc. M109.096404

36. Lin MT, Beal MF (2006) Mitochondrial dysfunction and oxidative stress in neurodegenerative diseases. Nature 443:787-795. doi:10.1038/nature05292

37. Gandhi S, Abramov AY (2012) Mechanism of oxidative stress in neurodegeneration. Oxid Med Cell Longev 2012:428010. doi: $10.1155 / 2012 / 428010$

38. Tansey MG, McCoy MK, Frank-Cannon TC (2007) Neuroinflammatory mechanisms in Parkinson's disease: potential environmental triggers, pathways, and targets for early therapeutic intervention. Exp Neurol 208:1-25. doi:10.1016/j.expneurol.2007.07.004

39. Miller RL, James-Kracke M, Sun GY, Sun AY (2009) Oxidative and inflammatory pathways in Parkinson's disease. Neurochem Res 34:55-65. doi:10.1007/s11064-008-9656-2

40. Mariani E, Polidori MC, Cherubini A, Mecocci P (2005) Oxidative stress in brain aging, neurodegenerative and vascular diseases: an overview. J Chromatogr B Analyt Technol Biomed Life Sci 827:65-75. doi:10.1016/j.jchromb.2005.04.023

41. Bano S, Parihar MS (1997) Reduction of lipid peroxidation in different brain regions by a combination of alpha-tocopherol and ascorbic acid. J Neural Transm 104:1277-1286. doi:10.100 7/BF01294728

42. Lu T, Pan Y, Kao S-Y et al (2004) Gene regulation and DNA damage in the ageing human brain. Nature 429:883-891. doi:10.1038/nature02661

43. Martinez FO, Helming L, Gordon S (2009) Alternative activation of macrophages: an immunologic functional perspective. Annu Rev Immunol 27:451-483. doi:10.1146/annurev.immunol .021908 .132532

44. Recalcati S, Locati M, Gammella E et al (2012) Iron levels in polarized macrophages: regulation of immunity and autoimmunity. Autoimmun Rev 11:883-889. doi:10.1016/j.autrev.2012.03.003

45. Recalcati S, Locati M, Marini A et al (2010) Differential regulation of iron homeostasis during human macrophage polarized activation. Eur J Immunol 40:824-835. doi:10.1002/ eji.200939889

46. Jimenez S, Baglietto-Vargas D, Caballero C et al (2008) Inflammatory response in the hippocampus of PS1M146L/APP751SL mouse model of Alzheimer's disease: age-dependent switch in the microglial phenotype from alternative to classic. J Neurosci 28:11650-11661. doi:10.1523/JNEUROSCI.3024-08.2008

47. Urrutia P, Aguirre P, Esparza A et al (2013) Inflammation alters the expression of DMT1, FPN1 and hepcidin, and it causes iron accumulation in central nervous system cells. J Neurochem. doi:10.1111/jnc.12244

48. Koppula S, Kumar H, Kim IS, Choi D-K (2012) Reactive oxygen species and inhibitors of inflammatory enzymes, NADPH oxidase, and iNOS in experimental models of Parkinson's disease. Mediators Inflamm 2012:823902. doi: $10.1155 / 2012 / 823902$

49. Bonneh-Barkay D, Reaney SH, Langston WJ, Di Monte DA (2005) Redox cycling of the herbicide paraquat in microglial cultures. Brain Res Mol Brain Res 134:52-56. doi:10.1016/j.m olbrainres.2004.11.005

50. Miller RL, Sun GY, Sun AY (2007) Cytotoxicity of paraquat in microglial cells: involvement of PKCdelta- and 
ERK1/2-dependent NADPH oxidase. Brain Res 1167:129-139. doi:10.1016/j.brainres.2007.06.046

51. Wu X-F, Block ML, Zhang W et al (2005) The role of microglia in paraquat-induced dopaminergic neurotoxicity. Antioxid Redox Signal 7:654-661. doi:10.1089/ars.2005.7.654

52. Villarán RF, Espinosa-Oliva AM, Sarmiento M et al (2010) Ulcerative colitis exacerbates lipopolysaccharide-induced damage to the nigral dopaminergic system: potential risk factor in Parkinson's disease. J Neurochem 114:1687-1700. doi:10.1111/j.1471-4159.2010.06879.x

53. Hernández-Romero MC, Delgado-Cortés MJ, Sarmiento $M$ et al (2012) Peripheral inflammation increases the deleterious effect of CNS inflammation on the nigrostriatal dopaminergic system. Neurotoxicology 33:347-360. doi:10.1016/j.neuro.2012.01.018

54. Dugas B, Mossalayi MD, Damais C, Kolb JP (1995) Nitric oxide production by human monocytes: evidence for a role of CD23. Immunol Today 16:574-580. doi:10.1016/0167-5699(95)80080-8

55. Liberatore GT, Jackson-Lewis V, Vukosavic S et al (1999) Inducible nitric oxide synthase stimulates dopaminergic neurodegeneration in the MPTP model of Parkinson disease. Nat Med 5:1403-1409. doi:10.1038/70978

56. Wu DC, Jackson-Lewis V, Vila M et al (2002) Blockade of microglial activation is neuroprotective in the 1-methyl-4-phenyl-1,2,3,6-tetrahydropyridine mouse model of Parkinson disease. J Neurosci 22:1763-1771

57. Iravani MM, Kashefi K, Mander P et al (2002) Involvement of inducible nitric oxide synthase in inflammation-induced dopaminergic neurodegeneration. Neuroscience 110:49-58. doi:10.1016/S0306-4522(01)00562-0

58. Arimoto T, Bing G (2003) Up-regulation of inducible nitric oxide synthase in the substantia nigra by lipopolysaccharide causes microglial activation and neurodegeneration. Neurobiol Dis 12:35-45. doi:10.1016/S0969-9961(02)00017-7

59. Neher JJ, Neniskyte U, Zhao J-W et al (2011) Inhibition of microglial phagocytosis is sufficient to prevent inflammatory neuronal death. J Immunol 186:4973-4983. doi:10.4049/jimm unol.1003600

60. Reif DW, Simmons RD (1990) Nitric oxide mediates iron release from ferritin. Arch Biochem Biophys 283:537-541. doi:10.1016/0003-9861(90)90680-W

61. Bartzokis G, Cummings JL, Markham CH et al (1999) MRI evaluation of brain iron in earlier- and later-onset Parkinson's disease and normal subjects. Magn Reson Imaging 17:213-222. doi:10.1016/S0730-725X(98)00155-6

62. Bartzokis G, Tishler TA (2000) MRI evaluation of basal ganglia ferritin iron and neurotoxicity in Alzheimer's and Huntington's disease. Cell Mol Biol (Noisy-le-grand) 46:821-833

63. Crichton RR, Dexter DT, Ward RJ (2011) Brain iron metabolism and its perturbation in neurological diseases. J Neural Transm 118:301-314. doi:10.1007/s00702-010-0470-z

64. Persidsky Y, Ramirez SH, Haorah J, Kanmogne GD (2006) Blood-brain barrier: structural components and function under physiologic and pathologic conditions. J Neuroimmune Pharmacol 1:223-236. doi:10.1007/s11481-006-9025-3

65. Hawkins BT, Davis TP (2005) The blood-brain barrier/neurovascular unit in health and disease. Pharmacol Rev 57:173-185. doi:10.1124/pr.57.2.4

66. Abbott NJ, Patabendige AAK, Dolman DEM et al (2010) Structure and function of the blood-brain barrier. Neurobiol Dis 37:13-25. doi:10.1016/j.nbd.2009.07.030

67. Yu D, Corbett B, Yan Y et al (2012) Early cerebrovascular inflammation in a transgenic mouse model of Alzheimer's disease. Neurobiol Aging. doi:10.1016/j.neurobiolag ing.2012.02.023
68. Carvey PM, Zhao CH, Hendey B et al (2005) 6-Hydroxydopamine-induced alterations in blood-brain barrier permeability. Eur J Neurosci 22:1158-1168. doi:10.1111/j.1460-9568.2005.04281.x

69. Duran-Vilaregut J, del Valle J, Camins A et al (2009) Bloodbrain barrier disruption in the striatum of rats treated with 3-nitropropionic acid. Neurotoxicology 30:136-143. doi:10.1016/j.neuro.2008.10.007

70. Rodrigues MCO, Hernandez-Ontiveros DG, Louis MK et al (2012) Neurovascular aspects of amyotrophic lateral sclerosis. Int Rev Neurobiol 102:91-106. doi:10.1016/ B978-0-12-386986-9.00004-1

71. Faucheux BA, Bonnet AM, Agid Y, Hirsch EC (1999) Blood vessels change in the mesencephalon of patients with Parkinson's disease. Lancet 353:981-982. doi:10.1016/ S0140-6736(99)00641-8

72. Ryu JK, McLarnon JG (2009) A leaky blood-brain barrier, fibrinogen infiltration and microglial reactivity in inflamed Alzheimer's disease brain. J Cell Mol Med 13:2911-2925. doi:10.1111/j.1582-4934.2008.00434.x

73. Garbuzova-Davis S, Saporta S, Haller E et al (2007) Evidence of compromised blood-spinal cord barrier in early and late symptomatic SOD1 mice modeling ALS. PLoS One 2:e1205. doi:10.1371/journal.pone.0001205

74. Storkebaum E, Quaegebeur A, Vikkula M, Carmeliet $P$ (2011) Cerebrovascular disorders: molecular insights and therapeutic opportunities. Nat Neurosci 14:1390-1397. doi:10.1038/nn.2947

75. Biron KE, Dickstein DL, Gopaul R, Jefferies WA (2011) Amyloid triggers extensive cerebral angiogenesis causing blood-brain barrier permeability and hypervascularity in Alzheimer's disease. PLoS One 6:e23789. doi:10.1371/ journal.pone.0023789

76. Biron KE, Dickstein DL, Gopaul R et al (2013) Cessation of neoangiogenesis in Alzheimer's disease follows amyloid-beta immunization. Sci Rep 3:1354. doi:10.1038/srep01354

77. Kartikasari AER, Georgiou NA, Visseren FLJ et al (2004) Intracellular labile iron modulates adhesion of human monocytes to human endothelial cells. Arterioscler Thromb Vasc Biol 24:2257-2262. doi:10.1161/01.ATV.0000147406.00871.b3

78. Kartikasari AER, Visseren FLJ, Marx JJM et al (2009) Intracellular labile iron promotes firm adhesion of human monocytes to endothelium under flow and transendothelial migration: iron and monocyte-endothelial cell interactions. Atherosclerosis 205:369-375. doi:10.1016/j.atherosclerosis.2008.12.031

79. Bennett RM, Williams ED, Lewis SM, Holt PJ (1973) Synovial iron deposition in rheumatoid arthritis. Arthritis Rheum 16:298-304. doi:10.1002/art.1780160303

80. Ogilvie-Harris DJ, Fornaiser VL (1980) Synovial iron deposition in osteoarthritis and rheumatoid arthritis. J Rheumatol $7: 30-36$

81. Ahmadzadeh N, Shingu M, Nobunaga M (1989) Iron-binding proteins and free iron in synovial fluids of rheumatoid arthritis patients. Clin Rheumatol 8:345-351. doi:10.1007/BF02030347

82. Morris CJ, Blake DR, Wainwright AC, Steven MM (1986) Relationship between iron deposits and tissue damage in the synovium: an ultrastructural study. Ann Rheum Dis 45:21-26. doi:10.1136/ard.45.1.21

83. Schumacher HR (1964) Hemochromatosis and arthritis. Arthritis Rheum 7:41-50. doi:10.1002/art.1780070106

84. Dabbagh AJ, Trenam CW, Morris CJ, Blake DR (1993) Iron in joint inflammation. Ann Rheum Dis 52:67-73. doi:10.1136/ $\operatorname{ard} .52 .1 .67$

85. Roosendaal G, Mauser-Bunschoten EP, De Kleijn P et al (1998) Synovium in haemophilic arthropathy. Haemophilia 4:502-505. doi:10.1046/j.1365-2516.1998.440502.x 
86. Schumacher HR, Straka PC, Krikker MA, Dudley AT (1988) The arthropathy of hemochromatosis. Recent studies. Ann N Y Acad Sci 526:224-233. doi:10.1111/j.1749-6632.1988.tb55508.x

87. Stadler N, Lindner RA, Davies MJ (2004) Direct detection and quantification of transition metal ions in human atherosclerotic plaques: evidence for the presence of elevated levels of iron and copper. Arterioscler Thromb Vasc Biol 24:949-954. doi:10.116 1/01.ATV.0000124892.90999.cb

88. Hansson GK (2009) Atherosclerosis-an immune disease: the Anitschkov Lecture 2007. Atherosclerosis 202:2-10. doi:10.1016/j.atherosclerosis.2008.08.039

89. Ross R (1999) Atherosclerosis-an inflammatory disease. N Engl J Med 340:115-126. doi:10.1056/NEJM199901143400207

90. Zacharski LR, Gerhard GS (2003) Atherosclerosis: a manifestation of chronic iron toxicity? Vasc Med 8:153-155. doi:10.1191/1358863x03vm492ed

91. Kehrer JP (2000) The Haber-Weiss reaction and mechanisms of toxicity. Toxicology 149:43-50. doi:10.1016/ S0300-483X(00)00231-6

92. Papanikolaou G, Pantopoulos K (2005) Iron metabolism and toxicity. Toxicol Appl Pharmacol 202:199-211. doi:10.1016/j.taap.2004.06.021

93. Park UJ, Lee YA, Won SM et al (2011) Blood-derived iron mediates free radical production and neuronal death in the hippocampal CA1 area following transient forebrain ischemia in rat. Acta Neuropathol 121:459-473. doi:10.1007/ s00401-010-0785-8

94. Won SM, Lee JH, Park UJ et al (2011) Iron mediates endothelial cell damage and blood-brain barrier opening in the hippocampus after transient forebrain ischemia in rats. Exp Mol Med 43:121-128. doi:10.3858/emm.2011.43.2.020

95. Man S, Ubogu EE, Ransohoff RM (2007) Inflammatory cell migration into the central nervous system: a few new twists on an old tale. Brain Pathol 17:243-250. doi:10.1111/j.1750-3639.2007.00067.x

96. Humpel C (2008) Basolateral aggregated rat amyloidbeta(1-42) potentiates transmigration of primary rat monocytes through a rat blood-brain barrier. Curr Neurovasc Res 5:185-192. doi:10.2174/156720208785425701

97. Wirenfeldt M, Dissing-Olesen L, Anne Babcock A et al (2007) Population control of resident and immigrant microglia by mitosis and apoptosis. Am J Pathol 171:617-631. doi:10.2353/a jpath.2007.061044

98. Tabas I, Seimon T, Timmins J et al (2009) Macrophage apoptosis in advanced atherosclerosis. Ann N Y Acad Sci 1173(Suppl 1):E40-E45. doi:10.1111/j.1749-6632.2009.04957.x

99. Uversky VN, Li J, Fink AL (2001) Metal-triggered structural transformations, aggregation, and fibrillation of human alphasynuclein. A possible molecular NK between Parkinson's disease and heavy metal exposure. J Biol Chem 276:44284-44296. doi:10.1074/jbc.M105343200

100. Riedlerer PF (2004) Views on neurodegeneration as a basis for neuroprotective strategies. Med Sci Monit 10:RA287-90

101. Moser KV, Humpel C (2007) Primary rat monocytes migrate through a BCEC-monolayer and express microglia-markers at the basolateral side. Brain Res Bull 74:336-343. doi:10.1016/j. brainresbull.2007.07.004

102. Sawada M, Imamura K, Nagatsu T (2006) Role of cytokines in inflammatory process in Parkinson's disease. J Neural Transm Suppl pp 373-381. doi: 10.1007/978-3-211-45295-0_57

103. Honda S, Sasaki Y, Ohsawa K et al (2001) Extracellular ATP or ADP induce chemotaxis of cultured microglia through Gi/ocoupled P2Y receptors. J Neurosci 21:1975-1982

104. El Khoury J, Luster AD (2008) Mechanisms of microglia accumulation in Alzheimer's disease: therapeutic implications. Trends Pharmacol Sci 29:626-632. doi:10.1016/j. tips.2008.08.004

105. Suzumura A (2013) Neuron-microglia interaction in neuroinflammation. Curr Protein Pept Sci 14:16-20

106. Rathnasamy G, Ling E-A, Kaur C (2011) Iron and iron regulatory proteins in amoeboid microglial cells are linked to oligodendrocyte death in hypoxic neonatal rat periventricular white matter through production of proinflammatory cytokines and reactive oxygen/nitrogen species. J Neurosci 31:17982-17995. doi:10.1523/JNEUROSCI.2250-11.2011

107. Yoshida T, Tanaka M, Sotomatsu A, Hirai S (1995) Activated microglia cause superoxide-mediated release of iron from ferritin. Neurosci Lett 190:21-24. doi:10.1016/0304-3940(95)11490-N

108. Moos T, Morgan EH (2000) Transferrin and transferrin receptor function in brain barrier systems. Cell Mol Biol (Noisy-legrand) 20:77-95. doi:10.1023/A:1006948027674

109. Bradbury MW (1997) Transport of iron in the blood-braincerebrospinal fluid system. J Neurochem 69:443-454. doi:10.1046/j.1471-4159.1997.69020443.x

110. Rite I, Machado A, Cano J, Venero JL (2007) Blood-brain barrier disruption induces in vivo degeneration of nigral dopaminergic neurons. J Neurochem 101:1567-1582. doi:10.1111/j.1471-4159.2007.04567.x

111. Burdo JR, Menzies SL, Simpson IA et al (2001) Distribution of divalent metal transporter 1 and metal transport protein 1 in the normal and Belgrade rat. J Neurosci Res 66:1198-1207. doi: $10.1002 / j n r .1256$

112. Wu LJ-C, Leenders AGM, Cooperman S et al (2004) Expression of the iron transporter ferroportin in synaptic vesicles and the blood-brain barrier. Brain Res 1001:108-117. doi:10.1016/j.brainres.2003.10.066

113. Boserup MW, Lichota J, Haile D, Moos T (2011) Heterogenous distribution of ferroportin-containing neurons in mouse brain. Biometals 24:357-375. doi:10.1007/ s10534-010-9405-2

114. McKie AT, Marciani P, Rolfs A et al (2000) A novel duodenal iron-regulated transporter, IREG1, implicated in the basolateral transfer of iron to the circulation. Mol Cell 5:299-309. doi:10.1016/S1097-2765(00)80425-6

115. De Domenico I, Zhang TY, Koening CL et al (2010) Hepcidin mediates transcriptional changes that modulate acute cytokine-induced inflammatory responses in mice. J Clin Invest 120:2395-2405. doi:10.1172/JCI42011

116. Nemeth E, Tuttle MS, Powelson J et al (2004) Hepcidin regulates cellular iron efflux by binding to ferroportin and inducing its internalization. Science 306:2090-2093. doi:10.1126/ science. 1104742

117. Wang S-M, Fu L-J, Duan X-L et al (2010) Role of hepcidin in murine brain iron metabolism. Cell Mol Life Sci 67:123-133. doi:10.1007/s00018-009-0167-3

118. Moos T, Rosengren Nielsen T, Skjørringe T, Morgan EH (2007) Iron trafficking inside the brain. J Neurochem 103:1730-1740. doi:10.1111/j.1471-4159.2007.04976.x

119. Schwartz M, Shechter R (2010) Systemic inflammatory cells fight off neurodegenerative disease. Nat Rev Neurol 6:405-410. doi:10.1038/nrneurol.2010.71

120. Aisen PS, Davis KL, Berg JD et al (2000) A randomized controlled trial of prednisone in Alzheimer's disease. Alzheimer's Disease Cooperative Study. Neurology 54:588-593. doi:10.121 2/WNL.54.3.588

121. Klegeris A, McGeer PL (2005) Non-steroidal anti-inflammatory drugs (NSAIDs) and other anti-inflammatory agents in the treatment of neurodegenerative disease. Curr Alzheimer Res 2:355-365. doi:10.2174/1567205054367883 
122. Bonuccelli U, Del Dotto P (2006) New pharmacologic horizons in the treatment of Parkinson disease. Neurology 67:S30-S38. doi:10.1212/WNL.67.7_suppl_2.S30

123. Tomás-Camardiel M, Rite I, Herrera AJ et al (2004) Minocycline reduces the lipopolysaccharide-induced inflammatory reaction, peroxynitrite-mediated nitration of proteins, disruption of the blood-brain barrier, and damage in the nigral dopaminergic system. Neurobiol Dis 16:190-201. doi:10.1016/j.nbd.2004.01.010

124. Rodnitzky RL (2012) Upcoming treatments in Parkinson's disease, including gene therapy. Parkinsonism Relat Disord 18(Suppl 1):S37-S40. doi:10.1016/S1353-8020(11)70014-1

125. Stack EC, Ferrante RJ (2007) Huntington's disease: progress and potential in the field. Expert Opin Investig Drugs 16:19331953. doi:10.1517/13543784.16.12.1933

126. Chen C-M (2011) Mitochondrial dysfunction, metabolic deficits, and increased oxidative stress in Huntington's disease. Chang Gung Med J 34:135-152

127. Zhang WJ, Frei B (2003) Intracellular metal ion chelators inhibit TNFalpha-induced SP-1 activation and adhesion molecule expression in human aortic endothelial cells. Free Radic Biol Med 34:674-682. doi:10.1016/S0891-5849(02)01375-8

128. Lee TS, Shiao MS, Pan CC, Chau LY (1999) Iron-deficient diet reduces atherosclerotic lesions in apoE-deficient mice. Circulation 99:1222-1229. doi:10.1161/01.CIR.99.9.1222

129. Araujo JA, Romano EL, Brito BE et al (1995) Iron overload augments the development of atherosclerotic lesions in rabbits. Arterioscler Thromb Vasc Biol 15:1172-1180. doi:10.1161/01. ATV.15.8.1172

130. Minqin R, Rajendran R, Pan N et al (2005) The iron chelator desferrioxamine inhibits atherosclerotic lesion development and decreases lesion iron concentrations in the cholesterol-fed rabbit. Free Radic Biol Med 38:1206-1211. doi:10.1016/j.freeradb iomed.2005.01.008

131. Zhang WJ, Wei H, Frei B (2010) The iron chelator, desferrioxamine, reduces inflammation and atherosclerotic lesion development in experimental mice. Exp Biol Med (Maywood) 235:633-641. doi:10.1258/ebm.2009.009229

132. Hider RC, Roy S, Ma YM et al (2011) The potential application of iron chelators for the treatment of neurodegenerative diseases. Metallomics 3:239-249. doi:10.1039/c0mt00087f

133. Youdim MBH, Stephenson G, Ben Shachar D (2004) Ironing iron out in Parkinson's disease and other neurodegenerative diseases with iron chelators: a lesson from 6-hydroxydopamine and iron chelators, desferal and VK-28. Ann N Y Acad Sci 1012:306-325. doi:10.1196/annals.1306.025

134. Dexter DT, Statton SA, Whitmore C et al (2011) Clinically available iron chelators induce neuroprotection in the 6-OHDA model of Parkinson's disease after peripheral administration. J Neural Transm 118:223-231. doi:10.1007/s00702-010-0531-3

135. Fredenburg AM, Sethi RK, Allen DD, Yokel RA (1996) The pharmacokinetics and blood-brain barrier permeation of the chelators 1,2 dimethyl-, 1,2 diethyl-, and 1-[ethan-1'ol]2-methyl-3-hydroxypyridin-4-one in the rat. Toxicology 108:191-199

136. Zorzi G, Zibordi F, Chiapparini L et al (2011) Iron-related MRI images in patients with pantothenate kinase-associated neurodegeneration (PKAN) treated with deferiprone: results of a phase II pilot trial. Mov Disord 26:1756-1759. doi: $10.1002 / \mathrm{mds} .23751$

137. Pratini NR, Sweeters N, Vichinsky E, Neufeld JA (2013) Treatment of classic pantothenate kinase-associated neurodegeneration with deferiprone and intrathecal baclofen. Am J Phys Med Rehabil. doi:10.1097/PHM.0b013e318282d209

138. Connor JR, Menzies SL, St Martin SM, Mufson EJ (1992) A histochemical study of iron, transferrin, and ferritin in
Alzheimer's diseased brains. J Neurosci Res 31:75-83. doi:10.1 002/jnr.490310111

139. Lopes KO, Sparks DL, Streit WJ (2008) Microglial dystrophy in the aged and Alzheimer's disease brain is associated with ferritin immunoreactivity. Glia 56:1048-1060. doi:10.1002/ glia. 20678

140. Grundke-Iqbal I, Fleming J, Tung YC et al (1990) Ferritin is a component of the neuritic (senile) plaque in Alzheimer dementia. Acta Neuropathol 81:105-110. doi:10.1007/BF00334497

141. Quintana C, Bellefqih S, Laval JY et al (2006) Study of the localization of iron, ferritin, and hemosiderin in Alzheimer's disease hippocampus by analytical microscopy at the subcellular level. J Struct Biol 153:42-54. doi:10.1016/j.jsb.2005.11.001

142. Singh S, Kushwah AS, Singh R et al (2012) Current therapeutic strategy in Alzheimer's disease. Eur Rev Med Pharmacol Sci 16:1651-1664

143. Duan Y, Dong S, Gu F et al (2012) Advances in the pathogenesis of Alzheimer's disease: focusing on tau-mediated neurodegeneration. Transl Neurodegener 1:24. doi:10.1186/2047-9158-1-24

144. Youdim MB, Ben-Shachar D, Riederer P (1989) Is Parkinson's disease a progressive siderosis of substantia nigra resulting in iron and melanin induced neurodegeneration? Acta Neurol Scand Suppl 126:47-54. doi:10.1111/j.1600-0404.1989. tb01782.x

145. Hirsch EC, Brandel JP, Galle P et al (1991) Iron and aluminum increase in the substantia nigra of patients with Parkinson's disease: an X-ray microanalysis. J Neurochem 56:446-451. doi:10.1111/j.1471-4159.1991.tb08170.x

146. Gorell JM, Ordidge RJ, Brown GG et al (1995) Increased ironrelated MRI contrast in the substantia nigra in Parkinson's disease. Neurology 45:1138-1143. doi:10.1212/WNL.45.6.1138

147. Vymazal J, Righini A, Brooks RA et al (1999) T1 and T2 in the brain of healthy subjects, patients with Parkinson disease, and patients with multiple system atrophy: relation to iron content. Radiology 211:489-495

148. Jellinger K, Paulus W, Grundke-Iqbal I et al (1990) Brain iron and ferritin in Parkinson's and Alzheimer's diseases. J Neural Transm Park Dis Dement Sect 2:327-340. doi:10.1007 /BF02252926

149. Hirsch EC (2006) Altered regulation of iron transport and storage in Parkinson's disease. J Neural Transm Suppl 201-204. doi: 10.1007/978-3-211-33328-0_21

150. Mirza B, Hadberg H, Thomsen P, Moos T (2000) The absence of reactive astrocytosis is indicative of a unique inflammatory process in Parkinson's disease. Neuroscience 95:425-432. doi:10.1016/S0306-4522(99)00455-8

151. de Lau LM, Breteler MM (2006) Epidemiology of Parkinson's disease. Lancet Neurol 5:525-535. doi:10.1016/ S1474-4422(06)70471-9

152. Antony PMA, Diederich NJ, Krüger R, Balling R (2013) The hallmarks of Parkinson's disease. FEBS J. doi:10.1111/f ebs. 12335

153. Dumas EM, Versluis MJ, van den Bogaard SJA et al (2012) Elevated brain iron is independent from atrophy in Huntington's disease. Neuroimage 61:558-564. doi:10.1016/j.neuroim age.2012.03.056

154. Simmons DA, Casale M, Alcon B et al (2007) Ferritin accumulation in dystrophic microglia is an early event in the development of Huntington's disease. Glia 55:1074-1084. doi:10.1002/ glia.20526

155. Ha AD, Fung VSC (2012) Huntington's disease. Curr Opin Neurol 25:491-498. doi:10.1097/WCO.0b013e3283550c97

156. Imon Y, Yamaguchi S, Yamamura $Y$ et al (1995) Low intensity areas observed on $\mathrm{T} 2$-weighted magnetic resonance imaging of the cerebral cortex in various neurological diseases. J Neurol Sci 134(Suppl):27-32. doi:10.1016/0022-510X(95)00205-G 
157. Kwan JY, Jeong SY, Van Gelderen P et al (2012) Iron accumulation in deep cortical layers accounts for MRI signal abnormalities in ALS: correlating 7 Tesla MRI and pathology. PLoS One 7:e35241. doi:10.1371/journal.pone.0035241

158. Yiangou Y, Facer P, Durrenberger $P$ et al (2006) COX-2, $\mathrm{CB} 2$ and P2X7-immunoreactivities are increased in activated microglial cells/macrophages of multiple sclerosis and amyotrophic lateral sclerosis spinal cord. BMC Neurol 6:12. doi:10.1186/1471-2377-6-12

159. Boillée S, Vande Velde C, Cleveland DW (2006) ALS: a disease of motor neurons and their nonneuronal neighbors. Neuron 52:39-59. doi:10.1016/j.neuron.2006.09.018

160. Ludolph AC, Brettschneider J, Weishaupt JH (2012) Amyotrophic lateral sclerosis. Curr Opin Neurol 25:530-535. doi:10 .1097/WCO.0b013e328356d328

161. Lucato LT, Otaduy MCG, Barbosa ER et al (2005) Proton MR spectroscopy in Wilson disease: analysis of 36 cases. AJNR 26:1066-1071

162. Youdim MBH, Grünblatt E, Mandel S (2007) The copper chelator, D-penicillamine, does not attenuate MPTP induced dopamine depletion in mice. J Neural Transm 114:205-209. doi:10.1007/s00702-006-0499-1

163. Linder MC (2012) The relationship of copper to DNA damage and damage prevention in humans. Mutat Res 733:83-91. doi:10.1016/j.mrfmmm.2012.03.010
164. Suttle NF (2012) Copper imbalances in ruminants and humans: unexpected common ground. Adv Nutr 3:666-674. doi:10.3945/ an. 112.002220

165. Pfeiffer RF (2011) Wilson's disease. Handb Clin Neurol 100:681-709. doi:10.1016/B978-0-444-52014-2.00049-5

166. Koeppen AH, Dickson AC (2001) Iron in the HallervordenSpatz syndrome. Pediatr Neurol 25:148-155. doi:10.1016/ S0887-8994(01)00269-7

167. Hayflick SJ, Hartman M, Coryell J et al (2006) Brain MRI in neurodegeneration with brain iron accumulation with and without PANK2 mutations. AJNR 27:1230-1233

168. Hayflick SJ (2003) Unraveling the Hallervorden-Spatz syndrome: pantothenate kinase-associated neurodegeneration is the name. Curr Opin Pediatr 15:572-577. doi:10.1097/00008480-200312000-00005

169. Gregory A, Hayflick SJ (2011) Genetics of neurodegeneration with brain iron accumulation. Curr Neurol Neurosci Rep 11:254-261. doi:10.1007/s11910-011-0181-3

170. Hartig MB, Prokisch H, Meitinger T, Klopstock T (2012) Pantothenate kinase-associated neurodegeneration. Curr Drug Targets 13:1182-1189. doi:10.2174/138945012802002384 